\title{
Preventing bleeding and thromboembolic complications in atrial fibrillation patients undergoing surgery
}

\author{
Prevenindo complicações hemorrágicas e tromboembólicas de cirurgias em pacientes \\ anticoagulados por fibrilação atrial
}

Charles André

\begin{abstract}
Neurologists feel uneasy when asked about temporary anticoagulant interruption for surgery in patients with atrial fibrillation (AF). Rational decisions can be made based on current scientific evidence. Method: Critical review of international guidelines and selected references pertaining to bleeding and thromboembolism during periods of oral anticoagulant interruption. Results: Withholding oral anticoagulants leads to an increased risk of perioperative thromboembolism, depending on factors such as age, renal and liver function, previous ischemic events, heart failure etc. Surgeries are associated with a variable risk of bleeding - from minimal to very high. Individualized decisions about preoperative drug suspension, bridging therapy with heparin and time to restart oral anticoagulants after hemostasis can significantly reduce these opposing risks. Conclusion: Rational decisions can be made after discussion with all Health care team professionals involved and consideration of patient fears and expectations. Formal written protocols should help managing antithrombotic treatment during this delicate period.
\end{abstract}

Keywords: atrial fibrillation, oral anticoagulants, surgery, hemorrhage, thromboembolism.

\section{RESUMO}

Preocupação com sangramentos em pacientes anticoagulados por fibrilação atrial (FA) expõe os mesmos a riscos tromboembólicos que aumentam ainda mais quando anticoagulantes são suspensos para operações ou outras intervenções invasivas. Método: Revisão de Diretrizes internacionais e outras publicações sobre riscos relacionados a cirurgias. Resultados: A suspensão dos anticoagulantes aumenta o risco de complicações tromboembólicas na FA, em razão de idade, função renal e hepática, eventos isquêmicos prévios, cardiopatias etc. O risco hemorrágico das intervenções varia de mínimo a extremamente elevado. Decisões individualizadas sobre suspensão das drogas, recurso a anticoagulantes parenterais no preparo dos pacientes para cirurgia, tempo para retomada do anticoagulante oral após hemostasia reduzem significativamente estes riscos. Conclusão: Decisões racionais podem ser tomadas após discussão com os profissionais envolvidos - dentistas, anestesistas, cirurgiões; levando em conta inclusive temores e expectativas dos pacientes. Protocolos institucionais favorecem o manejo perioperatório seguro e devem ser discutidos com os pacientes e seus cuidadores.

Palavras-chave: anticoagulantes, cirurgia geral, fibrilação atrial, hemorragia, tromboembolia.

Individuals with atrial fibrillation $(\mathrm{AF})$ - especially older ones or those with previous thromboembolic episodes (cerebral or systemic) - have a high risk of embolic strokes. Except in the presence of specific contraindications, these patients should receive chronic therapy with oral anticoagulant drugs. However, neurologists frequently feel insecure in prescribing anticoagulants to AF patients, despite the publication of many guidelines reinforcing this need, allegedly because of continuing concerns about the risk of bleeding complications, especially intracranial hemorrhage (ICH).
AF patients nowadays live longer with multiple co-morbidities and over time frequently demand medical and surgical interventions associated with a variable risk of bleeding. One quarter of anticoagulated patients need temporary drug suspension in 2 years ${ }^{1}$. Simply withholding anticoagulants however implies in risk of new embolic events. Balancing the opposing risks of bleeding and embolism may seem empiric. The attending physicians are frequently asked by other professionals - surgeons, anesthesiologists, and dentists - authorization to temporarily withhold Warfarin so

Universidade Federal do Rio de Janeiro, Faculdade de Medicina, Serviço de Neurologia, Rio de Janeiro RJ, Brazil.

Correspondence: Charles André; Hospital Universitário Clementino Fraga Filho, Cidade Universitária, Ilha do Fundão; Rua Rodolpho Paulo Rocco, 255/sala 10E36; 21941-913 Rio de Janeiro RJ, Brasil; E-mail: dr.charles.andre@gmail.com

Conflict of interest: There is no conflict of interest to declare.

Received 06 January 2015; Received in final form 06 March 2015; Accepted 26 March 2015. 
patients can be submitted to various procedures. This conduct would be clearly inadequate in many instances.

The present text reviews the scientific evidences guiding rational antithrombotic management in FA patients who must be submitted to invasive interventions including surgery. The recommendations should also be useful to stroke patients with less common indications for chronic anticoagulation - e.g., atrial flutter or cerebral venous thrombosis. Patients with stroke caused by other mechanisms who are sometimes anticoagulated for other reasons, especially venous thromboembolism [(VTE) - including peripheral vein thrombosis and pulmonary embolism], may also need changes in anticoagulant strategy. It should be remembered however that typical preventive regimens for venous thrombosis exhibit minimal or no efficacy against arterial thromboembolism. The manuscript reviews the vitamin $\mathrm{K}$ antagonist Warfarin and the new oral anticoagulants [(NOACs): direct thrombin and factor Xa inhibitors] and is partially based in a number of recently published guidelines from American and European medical societies to which the interested reader is directed for more details $\mathrm{s}^{2,3,4,5,6,7,8,9,10}$.

\section{ATRIAL FIBRILLATION AND STROKE RISK}

Chronic or paroxysmal AF is responsible for a large number of thromboembolic events every year. The main affected area (up to $80 \%$ ) is the brain - 10 to $12 \%$ of cerebral infarcts $(\mathrm{CI})^{4,11}$. The frequency increases as age advances: the attributed risk in individuals with 80 years or more reaches $25 \%^{2,5,10,12}$. Risk is also greater in women (in all age groups: HR 1.14 [95\%CI, $1.07-1.22$ ]: $20.4 \%$ of CI in women vs. $15.6 \%$ in men) $)^{10,13,14}$. Women also tend to develop strokes in later ages, and the risk difference between genders concentrates in older $\mathrm{AF}$ patients ( $\geq 75$ years). These two variables - age and gender - are integrated in current predictive models such as the CHA2DS2-VASc (Table 1) ) $15,16,17,18^{\text {. }}$

Risk scales help define the best antithrombotic strategy in AF patients. The main scales used are presented in Table 1. Using for instance the CHADS2 model:

- low risk (score 0) - acetylsalicylic acid (ASA) 81-325 mg/day or no treatment (optimizing possible associated risk factors);

- medium risk (score 1) - ASA or Warfarin (consider patient preferences and hemorrhage risk);

- greater risk (score $\geq 2$ ) - Warfarin (International Normalized Ratio (INR) 2-3 [goal INR- 2.5]).

Recommendations are similar using the CHAD2DS2-VASc, with some authors suggesting the use of NOACs from a score of 1 or more ${ }^{19}$. CHAD2DS2-VASc probably better estimates risk in patients classified as low-risk using the CHADS2 model ${ }^{16,17,18}$.

The instruments used to stratify the annual risk of stroke recurrence in $\mathrm{AF}$ probably underestimate the actual
Table 1. Main scales for arterial thromboembolic risk evaluation in patients with atrial fibrillation.

\begin{tabular}{lccc}
\hline CHADS2 & & & CHA2DS2-VASc \\
\hline Score & Criteria & Score & Criteria \\
1 point & CHF & 1 point & CHF \\
1 point & Hypertension & 1 point & Hypertension \\
1 point & Age $>75$ years & 2 points & Age $>75$ years \\
1 point & Diabetes mellitus & 1 point & Diabetes mellitus \\
2 points & Stroke/TIA & 2 points & Stroke/TIA/systemic embolism \\
& & 1 point & Vascular disease \\
& & 1 point & Age 65-74 years \\
& & 1 point & Female gender \\
\hline Total Score & Annual risk(\%) & Total Score & Annual risk $(\%)$ \\
\hline 0 & 1.9 & 0 & 0 \\
1 & 2.8 & 1 & 1.3 \\
2 & 4.0 & 2 & 2.2 \\
3 & 5.9 & 3 & 3.2 \\
4 & 8.5 & 4 & 4.0 \\
5 & 12.5 & 5 & 6.7 \\
6 & 18.2 & 6 & 9.8 \\
& & 7 & 9.6 \\
& & 8 & 6.7 \\
& & 9 & 15.2 \\
\hline
\end{tabular}

CHF: congestive heart failure - signs and symptoms, confirmation by exams; Hypertension - resting BP > 140/90 mmHg in at least 2 moments or current pharmacological treatment; Diabetes mellitus - fasting glycemia >125 mg/dL or current pharmacological treatment; Stroke - any type of cerebral ischemia; Vascular disease - myocardial infarct/angina, peripheral arterial disease, aortic plaque... TIA: transient ischemic attack.

risk, most probably around 7 to $10 \%^{20}$. Any history of previous thromboembolic event - usually cerebral - is therefore a marker of high risk of recurrence. Except in cases with a strong contraindication such as recent severe hemorrhage or a persistent bleeding tendency these patients should be adequately anticoagulated. Besides the factors usually included in prediction scales such as coronary heart disease, congestive heart failure etc., the risk also increases with rheumatic valve disease; biological heart valves (any position) or aortic mechanical valves; and even more with mechanical mitral valves (the risk is particularly high with caged-ball or tilting disk models).

A difficult area is the diagnosis of paroxysmal AF. Some 10 to $12 \%$ of stroke patients will exhibit AF during the initial hospital stay, but at least 10 to $15 \%$ more may have paroxysmal episodes only evident after long monitoring periods. A series of methods for paroxysmal AF detection have been prospectively evaluated. Ambulatory monitoring for 30 days in individuals with cryptogenic CI revealed 11\% (7.6-15.7\%) of episodes persisting for at least 5 seconds $(6.7 \%$ for episodes $>30$ seconds), most frequently asymptomatic ${ }^{11}$. More than half of the episodes were detected only after 10 days of monitoring.

Other methods are being tested. Some researchers suggest teaching patients and family caregivers to evaluate the arterial pulse as to its frequency and regularity; preliminary studies show reasonable sensitivity and specificity in the identification of tachyarrhythmias and its differentiation from sinus rhythm after a brief training ${ }^{21}$. Detection of the 
arrhythmia should be followed by formal Electrocardiogram (EKG) exam that can even be done by telemetry ${ }^{22}$. The so-called event-Holter can be triggered by patients whenever they suspect the presence of the arrhythmia. These two techniques however tend to detect only a few episodes. In the study of Flint and cols referred above only $6 \%$ of the episodes detected by EKG monitoring were perceived by the patients ${ }^{11}$. Other methods of low availability that are not dependent on patient awareness have been proposed including subcutaneous cardiac monitors used for periods of many months. Using one of these systems in patients with cryptogenic CI, AF episodes of at least 30 seconds were detected 6 times more frequently than in a control group ( $8.9 \%$ vs. $1.4 \%$ ) after 6 months ( $12.4 \%$ vs. $2 \%$ in 12 months $)^{23}$.

A table including $\mathrm{AF}$ patients and other risk groups for thromboembolic complications has been developed (Table 2$)^{7,8}$. It can be used in surgical patients, although it is based on annual risk in clinical settings ${ }^{7}$. The risk of hemorrhage in anticoagulated patients can also be reasonably estimated using scales such as HAS-BLED (Table 3$)^{24,25}$. It should be highlighted that the same factors may increase the risks of both thromboembolism and hemorrhage ${ }^{26}$. Hence, therapeutic decisions should always be individualized and patients and relatives or caregivers should receive adequate instruction on the necessary care to help reduce bleeding risks - diet habits, scheduled laboratory controls, risks related to drug interactions and falls etc.

\section{EFFICACY AND USE OF ORAL ANTICOAGULANTS}

\section{Warfarin}

The efficacy of Warfarin in AF as compared to placebo is undisputable. In primary prevention, the risk reduction (RR) reaches $68 \%$ (annual risk $1.4 \%$ vs. $4.5 \%)^{27}$. ASA is also efficacious but much less $\mathrm{so}^{28}$. The differences between Warfarin and ASA are small only in young patients with non-rheumatic $\mathrm{AF}$ and without other risk factors ${ }^{29,30}$. After a thromboembolic event, the annual stroke risk falls with Warfarin from $12 \%$ to $4 \%$ (vs. placebo) ${ }^{31}$. This same study showed a clear advantage of Warfarin over ASA in patients eligible for anticoagulation.

The INR-goal for most patients is 2.5 (2.0-3.0). The first main studies accepted higher levels of anticoagulation ${ }^{27,28,29,30}$, but there is a strong consensus nowadays that the risk of bleeding complications increases disproportionally in patients with INR of 4 or more m,7,8. $^{3,8}$

\section{NOACs}

In the last decade large studies comparing NOACs (inhibitors of thrombin- dabigatran - and of Factor Xa - apixaban, rivaroxaban, edoxaban) and Warfarin in non-valvular $\mathrm{AF}$ were published. They are briefly summarized here. The comparison between dabigatran and Warfarin (RELY study: one third of patients with paroxysmal AF) showed non-inferiority of the new drug (combined outcome including systemic embolism and stroke: 1.69\%/year in the Warfarin group) of lower doses (110 mg b.i.d.: 1.53\%/year) and superiority of the higher doses tested (150 mg b.i.d.: 1.11\%/year), despite a very small increase in myocardial infarct rates and some increase in the risk of gastrointestinal hemorrhage ${ }^{19}$. The rates of major bleeding complications were similar in patients on Warfarin or on the higher doses of dabigatran but were lower in those on lower doses. Mortality was slightly less in those using the higher doses (3.64\%/year vs. 4.13\% for Warfarin - $\mathrm{p}=0.051)$. Some methodological difficulties of the study should however be mentioned: some $40 \%$ of both groups used ASA together with the anticoagulants; there was no blinding in the adjustment of Warfarin doses; in patients with stroke/transient ischemic attack (TIA) the risk reduction with dabigatran was not statistically significant even in higher doses (only non-inferiority was demonstrated).

Table 2. Risk stratification for perioperative thromboembolism (adapted from refs. 7 and 8).

\begin{tabular}{|c|c|c|c|}
\hline & Mechanical heart valve & Atrial fibrillation & Venous thromboembolism (VTE) \\
\hline High (> 10\%/year)* & $\begin{array}{l}\text { Any mitral valve prosthesis } \\
\text { Any caged-ball or tilting disc aortic } \\
\text { valve prosthesis } \\
\text { Recent (within } 6 \text { months) stroke or } \\
\text { transient ischemic attack }\end{array}$ & $\begin{array}{l}\text { CHADS } 2 \text { score of } 5 \text { or } 6 \\
\text { Recent (within } 3 \text { months) stroke or } \\
\text { transient ischemic attack } \\
\text { Rheumatic valvular heart disease }\end{array}$ & $\begin{array}{l}\text { Recent (within } 3 \text { months) VTE } \\
\text { Severe thrombophilia (e.g., } \\
\text { deficiency of protein C, protein S, } \\
\text { or antithrombin; antiphospholipid } \\
\text { antibodies; multiple abnormalities) }\end{array}$ \\
\hline Moderate (5-10\%/year) & $\begin{array}{l}\text { Bileaflet aortic valve prosthesis and } \\
\text { one or more of the following risk } \\
\text { factors: atrial fibrillation, prior stroke } \\
\text { or transient ischemic attack, } \\
\text { hypertension, diabetes, } \\
\text { congestive heart failure, age }>75 \text { y }\end{array}$ & $\begin{array}{l}\text { CHADS } 2 \text { score of } 3 \text { or } 4 \\
\text { VTE within the past } 3-12 \text { months } \\
\text { Non-severe thrombophilia (e.g., } \\
\text { heterozygous factor } V \text { Leiden or } \\
\text { prothrombin gene mutation) }\end{array}$ & $\begin{array}{c}\text { Recurrent VTE } \\
\text { Active cancer (treated within } 6 \\
\text { months or palliative) }\end{array}$ \\
\hline Low (<5\%/year) & $\begin{array}{l}\text { Bileaflet aortic valve prosthesis } \\
\text { without atrial fibrillation and no } \\
\text { other risk factors for stroke }\end{array}$ & $\begin{array}{c}\text { CHADS } 2 \text { score of } 0 \text { to } 2 \text { (assuming } \\
\text { no prior stroke or transient } \\
\text { ischemic attack) }\end{array}$ & $\begin{array}{c}\text { VTE }>12 \text { months previous and no } \\
\text { other risk factors }\end{array}$ \\
\hline
\end{tabular}

†Annual risks derived from clinical cohort studies and adapted for surgical patients. * Some patients otherwise included in other groups may be seen as having a very high risk. Examples include patients with lower CHADS2 scores but with a recent ( 3 months) stroke, remote VTE with serious consequences (pulmonary hypertension), or undergoing operations with specially high thromboembolic risk (carotid endarterectomy, coronary bypass or open heart surgery, vascular surgery) 
Table 3. HAS-BLED Score for annual risk of hemorrhage using oral anticoagulants.

\begin{tabular}{|c|c|}
\hline Criteria & Points \\
\hline $\mathrm{H}$ (Hypertension) & 1 \\
\hline \multicolumn{2}{|l|}{ A (Altered function) } \\
\hline renal & 1 \\
\hline liver & 1 \\
\hline S (previous Stroke) & 1 \\
\hline B (previous Bleed) & 1 \\
\hline L (Labile INR) & 1 \\
\hline$E$ (Elderly - age $>65$ years) & 1 \\
\hline \multicolumn{2}{|c|}{ D (Drugs predisposing to hemorrhage) } \\
\hline medicines & 1 \\
\hline alcohol & 1 \\
\hline Total Score & $\begin{array}{c}\text { Annual risk of bleeding under } \\
\text { anticoagulation, } \%\end{array}$ \\
\hline 0 (low risk) & $0.6-1.1 \%$ \\
\hline 1-2 (medium risk) & $1.9-3.2 \%$ \\
\hline$\geq 3$ (high risk) & $4.9-19.6 \%$ \\
\hline \multicolumn{2}{|c|}{$\begin{array}{l}\text { Definitions: Hypertension - uncontrolled, SBP }>160 \mathrm{~mm} \mathrm{Hg} \text {; A - chronic } \\
\text { renal failure (dialysis, renal transplant, } \mathrm{Cr}>2 \mathrm{mg} / \mathrm{dL} \text { ); chronic liver } \\
\text { disease or laboratory abnormalities (bilirubin }>2 \times \text { normal, AST or } \\
\text { ALT or gama-GT or alkaline phosphatase }>3 \times \text { normal); B - Bleeding } \\
\text { episodes or predisposition; L- elevated INR or INR values out of } \\
\text { therapeutic levels }>40 \% \text { of time; E - age }>65 \text { years; } \text { - medicines } \\
\text { (platelet antiaggregants, anti-inflammatory drugs), alcohol (weekly } \\
\text { consume } \geq 8 \text { doses). }\end{array}$} \\
\hline
\end{tabular}

A study comparing rivaroxaban $(20 \mathrm{mg} /$ daily $[15 \mathrm{mg}$ if $\mathrm{Cr} \mathrm{Cl} \mathrm{30-49} \mathrm{mL} / \mathrm{min}]$ ) and Warfarin in patients with slightly greater embolic risk (CHADS2 $\geq$, with previous embolic events in 55\%, congestive heart failure in $>60 \%$ ) demonstrated non-inferiority but not superiority (even in patients with a previous stroke) in reducing the annual thromboembolic risk: $2.1 \%$ vs. $2.4 \%$ (ROCKET-AF) ${ }^{32}$. Also, there was no significant difference in annual global risk of hemorrhage ( $14.9 \%$ vs. $14.5 \%$ ). Patients on rivaroxaban had more gastrointestinal hemorrhages $(3.2 \%$ vs. $2.2 \%)$ and more hemorrhages requiring blood transfusions (1.6\% vs. $1.3 \%$ /year); and lower rates of ICH ( $0.5 \%$ vs. $0.7 \% /$ year) and fatal hemorrhages $(0.2 \%$ vs. $0.5 \% /$ year $)$. An important critic has been made to this study: time spent with adequate levels of anticoagulation (55\%) in the Warfarin group (INR monitored by a blinded electronic system) was less than in many other studies.

Apixaban (5 mg b.i.d.; patients with Cr levels $>2.5 \mathrm{mg} / \mathrm{dL}$ excluded) has been compared to ASA (AVERROES - see ahead) and with Warfarin. In this case (ARISTOTLE), the annual risk of the composite outcome (hemorrhagic or ischemic stroke and systemic embolism) was significantly lower with apixaban $(1.27 \%$ vs. $1.60 \%)$ even in patients with a previous stroke/TIA ${ }^{33}$. There were also lower rates of severe hemorrhages (2.1 vs. $3.1 \%)$, $\mathrm{CH}(0.24 \%$ vs. $0.47 \%)$ and a slight reduction in global mortality ( $3.52 \%$ vs. $3.94 \%$ ), with no differences in rates of gastrointestinal hemorrhage.

A large trial (ENGAGE-AF) suggests similar results (non-inferiority for cerebral or systemic embolism and lower rates of major bleeding vs. Warfarin) using a novel anti-Xa drug, edoxaban, in two regimens (30 or $60 \mathrm{mg}$ once daily) ${ }^{34}$. Whatever the dose used it was halved if the patient's weight fell below $60 \mathrm{Kg}$ or if $\mathrm{Cr} \mathrm{Cl}$ was reduced (30-50 mL/min). In the intention-to-treat analysis, there was a trend for superiority using larger doses (HR ratio, 0.87; 97.5\%CI: 0.73-1.04; $\mathrm{p}=0.08$ ) and an opposite trend for inferiority with the lower doses (HR 1.13; 97.5\%CI: 0.96 to 1.34; $\mathrm{p}=0.10$ ). Both regimens were associated however with lower rates of severe hemorrhages, ICH and slightly lower mortality (significant difference with the higher dose regimen).

In summary, NOACs should be considered as an option on a par with Warfarin in most recently diagnosed non-valvular AF patients, taking into account clinical particulars (e.g., renal function [should be checked regularly during treatment], previous gastrointestinal hemorrhage) and patient preferences (inconvenience of multiple INR tests, cost etc.). Patients adequately anticoagulated with Warfarin (absence of bleeding or recurrent thromboembolism) should not routinely be switched to NOACs. Those with less than $60 \%$ of the time with an INR within therapeutic levels are probably at increased risk of thromboembolic or hemorrhagic events and constitute a group in which opting for a NOAC would probably be advantageous.

\section{Special situations}

Contraindication to anticoagulant treatment: there is no doubt about the efficacy of Warfarin or NOACs and their superiority over ASA (generally $100 \mathrm{mg} /$ day). Warfarin is also superior (annual rate of composite outcome - 3.9\% vs. 5.6\%) to the combination of aspirin and clopidogrel in primary prevention (ACTIVE W: AF plus at least one risk factor) ${ }^{35}$.

More recently, two studies evaluated strategies for AF patients with contraindications to Warfarin. In the first study (ACTIVE-A) double antiaggregation (ASA + clopidogrel) was compared to ASA only ${ }^{36}$ : the additional reduction in ischemic events with double therapy was basically neutralized by an increased risk of severe hemorrhages (RR 0.97; 95\%CI: $0.89-1.06 ; p=0.54$ for the composite outcome). It is therefore difficult to accept the IIa level AHA recommendation for double antiaggregation in patients with a contraindication to Warfarin treatment. Especially as another study with apixaban (5 mg b.i.d.) vs. ASA (AVERROES: patients with $\mathrm{Cr}>2.5 \mathrm{mg} / \mathrm{dL}$ excluded) showed superiority of apixaban (stroke or systemic embolism: annual rate $1.6 \%$ vs. $3.7 \%$ ) and absence of significant differences in adverse effects (severe hemorrhages, gastrointestinal bleedings, mortality ${ }^{37}$. The best strategy in this important group of patients remains under scrutiny. The availability of antagonists for both thrombin and Factor Xa inhibitors in the near future ${ }^{38,39}$ could possibly make the decision to start a NOAC the most appropriate in many cases.

Anticoagulants associated with platelet antiaggregants: an also much discussed question regards patients 
with coronary heart disease and stents with indication for anticoagulation because of $\mathrm{AF}$ (with or without previous stroke/TIA). Some $20 \%$ of patients with $\mathrm{AF}$ and stroke have symptomatic coronary disease (and many more will develop it in the future). The risks of the simultaneous use of Warfarin and antiplatelet drugs are well known and generally contraindicate their routine association. Triple therapy (double antiaggregant and anticoagulation) is associated with increased mortality and major bleeding risk and no additional reduction of thromboembolic events when compared to single antiaggregation with clopidogrel plus Warfarin treatment ${ }^{40}$. Some medical societies suggest, based in somewhat limited evidence, the concomitant use of Warfarin and ASA or clopidogrel/prasugrel in special situations for 12 months (CHADS2 $\geq 2$ ) or for an undefined time (acute coronary syndromes); and triple therapy for 12 months after pharmacological stent placement ${ }^{3,7,840,41}$. In AF anticoagulated patients undergoing angioplasty/stent placement, the antiplatelet drugs should be used in low doses; whenever possible, nonpharmacological stents should be preferred in anticoagulated patients (minimizing time on triple therapy).

There are fewer data on antiaggregation in patients using NOACs. Concomitant exposure to antiaggregants and NOACs markedly increases the risk of bleeding ${ }^{6}$. One third of patients included in large studies comparing Warfarin and theses drugs were receiving antiplatelet drugs, usually ASA in low doses. Specific trials comparing different strategies for double or triple therapy following percutaneous coronary interventions are under way (RE-DUAL-PCI, PIONEER AF-PCI). Even recognizing the empiric nature of this suggestion, the same strategy considering coronary risks and the time since the coronary events or stent implantation (and the differences between pharmacological and non-pharmacological stents) is recommended (see ref. 6 for further discussion).

Recurrence while on treatment with Warfarin: The ideal strategy here is still undefined. Increasing the INR (e.g., to 3) or adding antiplatelet drugs are strategies that do not seem to reduce the risk of recurrence but clearly add to the risk of severe hemorrhages. The use of NOACs in this setting has not been studied.

When to start treatment: the golden rule-primum non nocere - should prevail when deciding when to start the anticoagulant treatment after a stroke related to AF. The AHA/ASA Guidelines on secondary stroke prevention suggest that it is safe to postpone treatment up to two weeks in most patients ${ }^{3}$. Data pointing to a high risk of early recurrence of embolism in patients with AF-related stroke - up to $8.5 \%$ in 14 days -would suggest a need to start anticoagulation in a shorter time ${ }^{42}$. These data contrast however with a much lower risk indicated in very large prospective studies (CAST, IST) which found daily rates not exceeding $0.5 \%{ }^{43,44}$. The recommendation to withhold early anticoagulation is strongly based on results of a study including 449 patients with AF treated up to 30 hours after stroke onset ${ }^{42}$. Treatment with a LMWH - dalteparin - was not superior to that with ASA, with a low risk of $\mathrm{ICH}$ in both groups. Studies like the IST also indicate that the reduction in the risk of early recurrence (first 14 days) obtained by treatment with full doses of UFH is counterbalanced by an increased risk of $\mathrm{ICH}^{44}$. A meta-analysis of patients with cardioembolic stroke confirmed this idea ${ }^{45}$. In the IST, UFH treatment starting in the first 48 hours was also useless in the subgroup of patients with $\mathrm{AF}^{46}$.

Oral anticoagulation should probably be started earlier (first week) in individuals without an increased risk of symptomatic hemorrhage - large lesions, initial hemorrhagic transformation, general bleeding tendency, uncontrolled hypertension. The risk of early recurrence is greater for instance in patients with $\mathrm{CHF}$ or an acute anterior myocardial infarct, and this should also be considered in making the best individualized decision. In stroke patients with AF starting oral anticoagulants, there is a tendency to avoid initial bridging with UFH or LMWH. The bridging strategy does not confer obvious benefits (or increased risks) and prolongs hospital stay ${ }^{47}$.

\section{BLEEDING RISK AND MANAGEMENT OF ANTICOAGULATED PATIENTS UNDERGOING SURGERY}

Temporary withholding of anticoagulants is necessary in up to one quarter of patients in the first two years of use, most frequently because of fear of hemorrhage during surgery or invasive procedures ${ }^{1}$. Any period without anticoagulant poses an increased risk of thromboembolic events in AF patients ${ }^{48}$. Opposing risks vary according to age, associated cardiac disease, bleeding history and other patient factors (cancer, renal failure etc.). In patients with AF-related strokes the risk of recurrence is inversely related to the time elapsed since the ischemic event ${ }^{7,48}$. The intrinsic bleeding risk of the surgery or endoscopic procedure should also be carefully evaluated (Tables 4 and 5). Major surgeries and endoscopic procedures with mucosal or submucosal lesion resections are associated with a high bleeding risk $^{7,9}$. These patients should have anticoagulants (and clopidogrel) withheld. Superficial interventions (skin, teeth) or ophthalmological surgeries in sites without vascularization (such as cataract surgery with or without lens implantation) have a minimal risk and should be made without changes in the antithrombotic regimen. This last recommendation is especially relevant in individuals with a recent stroke/TIA (i.e., in the last 3-6 months).

Some principles should be kept in mind:

- The disappearance of antithrombotic effects (and hence the reversal of bleeding risk) depends on the time without the drug - this is greater with platelet antiaggregants (because of the expected platelet turnover) - around 7-10 days; and lower with NOACs (beware of renal insufficiency - see ahead). Warfarin has a half-life of 36 to 42 hours, 
and after 3 half-lives the expected residual anticoagulant activity is $12.5 \%$ (sometimes slower reduction in older patients). The INR is normal in almost all patients after 5 days without the drug. Some $7 \%$ of patients will have an INR over 1.5 on the day before surgery. In surgeries associated with a high bleeding risk they should receive oral vitamin $\mathrm{K}$ (1$2.5 \mathrm{mg}$ ), and have another test confirming INR normalization on the day of surgery ${ }^{49,50}$. Low risk procedures can be

Table 4. Bleeding risk in diverse procedures (modified from references 6, 7,9).

\begin{tabular}{|c|c|}
\hline $\begin{array}{l}\text { Minimal risk } \\
\text { (no change in } \\
\text { anticoagulant } \\
\text { regimen) }\end{array}$ & $\begin{array}{c}\text { Dental interventions * } \\
\text { Extraction of } 1-3 \text { teeth } \\
\text { Periodontal surgery } \\
\text { Drainage of abscess } \\
\text { Implants } \\
\text { Cataract } \\
\text { Endoscopy without intervention/biopsy } \\
\text { Superficial interventions }{ }^{\wedge}\end{array}$ \\
\hline $\begin{array}{l}\text { Low } \\
\text { bleeding risk }\end{array}$ & $\begin{array}{c}\text { Glaucoma ** } \\
\text { Endoscopy with biopsy } \\
\text { Prostate or bladder biopsy } \\
\text { Catheter ablation or electrophysiological study } \\
\text { Angiography } \\
\text { Pacemaker or ICD implantation *** }\end{array}$ \\
\hline $\begin{array}{l}\text { High bleeding } \\
\text { risk } k^{\star \star \star \star}\end{array}$ & $\begin{array}{c}\text { Complex radiofrequency ablation } \\
\text { Epidural or spinal anesthesia / diagnostic spinal tap } \\
\text { Thoracic surgery } \\
\text { Abdominal surgery } \\
\text { Major orthopedic surgery } \\
\text { Hepatic or renal biopsy } \\
\text { Transurethral prostate resection }\end{array}$ \\
\hline
\end{tabular}

* Mouth-washing/oral administration of tranexamic acid (Transamin ${ }^{\circledR}$ ) or epsilon-aminocaproic acid may reduce bleeding. An option in more extensive surgeries is to withhold Warfarin for 2-3 days. ^ Drainage of abscesses, excision of small skin lesions etc. ${ }^{*}$ Considered as minimal risk surgery by some authors, others suggest high risk (> 30\%) in anticoagulated patients (see text). $\star * *$ Can be associated with hematomas from deep infraclavicular fascial dissection/squeezing without suture; risk may be higher in complex anatomic settings (e.g., cardiac congenital malformations). $\star \star \star *$ Very high-risk surgery involves genitourinary system (transurethral resection, bladder tumor resection, nephrectomy and renal biopsy); resection of intestine (anastomosis bleeding) or large and sessile colonic polyps (late stalk bleeding - may be lessened with stalk clipping); highly vascularized organs (thyroid, spleen, liver); large areas of tissue lesion (cancer surgery, arthroplasty, reconstructive plastic surgery); and cardiac, intracranial or spinal surgery (small bleeding may have severe consequences). performed with an INR between 1.5 and 1.8, allowing for a shorter time without anticoagulation ${ }^{51}$.

- Bridging therapy with UFH or LMWH when oral antithrombotic treatment is withheld increase the risk of hemorrhages. This risk varies with the doses used (therapeutic doses > VTE prophylactic doses); and the time since the last preoperative dose or from surgery to treatment return. Postponing this return and reducing the doses used can minimize the bleeding risks but increase the time with a high risk of thromboembolic events. Bridging with heparin is considered in patients with a high risk of arterial thromboembolism (> 10\%/year) but not in those with low risk (<5\%). Decisions should be highly individualized in individuals with an intermediate risk (see Table 2).

- Bridging for the prevention of arterial thromboembolism only makes sense with full doses of heparin (UFH or LWH); studies using intermediate or "subtherapeutic" doses (e.g., enoxaparin $40 \mathrm{mg}$ b.i.d.) are scarce ${ }^{52}$. Table 6 summarizes the suggested conduct.

- Typical therapeutic and prophylactic doses: Unfractionated heparin (UFH) - continuous IV infusion to reach aPTT 1.5-2 times the control values, 5,000 IU SC every 8 or 12 hours; enoxaparin - $1 \mathrm{mg} / \mathrm{Kg}$ b.i.d., $40 \mathrm{mg} /$ daily dose.

- Time to effective antithrombotic action should be remembered when restarting treatment - minutes after UFH or ASA, many hours after Low molecular-weight heparin (LMWH) or NOACs, and many days after clopidogrel maintenance doses or Warfarin.

\section{Warfarin}

The scenario is somewhat more complicated for patients on Warfarin than those on NOACs, as the time to full disappearance of the anticoagulant effects is significantly longer - usually several days. Patients with a high risk of recurrent thromboembolism - such as those with a CHADS2 score of 5 or 6 , stroke/TIA in the last 3 months, severe CHF, rheumatic valvular disease or mechanical valves - usually receive bridging therapy with full doses of LMWH. An ambulatory strategy can reduce costs ${ }^{50,53}$. Heparin bridging is started when the INR is below 2.0, with the last dose given 24 hours before surgery; treatment is again started after assessment indicates full hemostasis, usually 48 hours

Table 5. Bleeding risk in gastrointestinal endoscopic procedures (from ref. 9).

\begin{tabular}{lc}
\hline Low risk* & Higher risk \\
\hline Diagnostic endoscopy (upper Gl tract, colonoscopy, flexible sigmoidoscopy), even with biopsy & Polipectomy \\
Endoscopic retrograde cholangiopancreatograhy without sphincterotomy & Biliary or pancreatic sphincterotomy \\
Endoscopic ultrasound without fine needle aspiration & Pneumatic or bougie dilation \\
Enteroscopy and diagnostic balloon-assisted enteroscopy & Percutaneous gastrostomy placement \\
Capsule endoscopy & Therapeutic balloon-assisted enteroscopy \\
Enteric stent deployment (without dilation) & Endoscopic ultrasound with fine needle aspiration \\
& Endoscopic hemostasis \\
& Tumor ablation (any technique) \\
Cystogastrostomy & Treatment of varices
\end{tabular}

* Most patients using ASA only should not withhold the drug (exception- mucosal/submucosal resections). Tienopiridines (clopidogrel, prasugrel etc.) are usually withheld electively, especially in complex procedures involving more than simple biopsies. 
Table 6. Bridging strategy for Warfarin treated patients according to hemorrhagic risk of surgery.

\begin{tabular}{|c|c|}
\hline High-risk & Minimal/low-risk \\
\hline Withhold Warfarin for 5-7 days and start full-dose LMWH or UFH & $\begin{array}{c}\text { Continue oral treatment (minimal-risk procedures) or withhold } \\
\text { Warfarin with heparin bridging (consider shorter periods of drug } \\
\text { suspension - e.g. 2-3 days) }\end{array}$ \\
\hline $\begin{array}{l}\text { Last dose of UFH (half-life } 30-120 \text { min) 4-6 hours before procedure; } \\
24 \text { hours for LMWH (residual anti-Xa activity in most patients after } 12 \mathrm{~h} \text { ) }\end{array}$ & $\begin{array}{c}\text { Last dose of UFH (half-life } 30-120 \mathrm{~min} \text { ) 4-6 hours before } \\
\text { procedure; } 24 \text { hours for LMWH (residual anti-Xa activity in most } \\
\text { patients after } 12 \mathrm{~h} \text { ) }\end{array}$ \\
\hline $\begin{array}{l}\text { Restart UFH or LMWH in 48-72 hours (after confirming full } \\
\text { hemostasis)* }\end{array}$ & Return UFH or LMWH after 24 hours \\
\hline
\end{tabular}

Restart Warfarin as soon as possible to shorten period under heparin treatment.

* If bleeding continues after 72 hours, consider low dose UFH or LMWH (only useful in VTE prevention) or restarting Warfarin treatment without bridging therapy.

after major interventions (24 hours after low-risk procedures) $)^{3,7}$. Similar recommendations apply to patients anticoagulated for recent VTE (i.e., $<3$ months) or with severe thrombophilias (e.g., antiphospholipid syndrome). Patients with an intermediate CHADS2 score (3 to 4) should have individualized decisions as to the use of LMWH after careful assessment of the specific surgery-related bleeding risks. The thromboembolic risk is probably similar in patients with VTE occurring 3 to 12 months before, more benign thrombophilias, or recent oncologic treatment. In most patients with an even lower risk (CHADS2 $=0$ to 2 without stroke/TIA, VTE $>12$ months before, and no other risk factors) it is probably safe to simply withhold Warfarin for 4 or 5 days. An INR is obtained on the day before planned surgery to assess the eventual need of oral vitamin $\mathrm{K}$ (usually 1-2.5 mg); and in the next morning just before surgery (fresh plasma given if necessary).

Surgical urgencies with a high bleeding risk should be postponed whenever possible for one or two days, giving fresh plasma and oral or intravenous Vitamin K to obtain reversal of anticoagulation. A normal point of care INR test - as suggested nowadays for the urgent evaluation of possible thrombolysis in hyperacute CI patients using Warfarin) probably suffices to assure that coagulation has returned to basal conditions. The point of care test tends to overestimate the INR when compared to standard INR analysis ${ }^{54}$.

Treatment with Warfarin after surgeries with a high bleeding risk should be reinitiated in patients with a medium to high risk of recurrent thromboembolic events as soon as a full hemostasis is secured, usually after 12 to 24 hours (not later) ${ }^{7}$. In very high-risk patients full doses of UFH or LMWH should be given while waiting for the INR to reach therapeutic levels. The first two weeks following any procedure here discussed are associated with an increased risk of both thromboembolic and hemorrhagic events, and frequent contact is always indicated after hospital discharge.

Minimal risk surgeries: these include a number of dental, skin and ocular interventions. Dental extraction and root canal treatment should be done without interruption of the anticoagulant (some patients may be more fearful of the hemorrhages than the thromboembolic risks and may prefer to withhold the drug for 2 to 3 days instead
[INR around 1.6-1.9]). Suturing and the use of fibrinolytics (e.g., mouth-washing/oral tranexamic acid [Transamin ${ }^{\circledR}$ ] $5 \mathrm{~mL} 10$ minutes before and 3-4 times a day for 1-2 days) reduce even further the bleeding risk ${ }^{55,56,57}$. Patients should be warned that some gingival oozing may persist for a few days, during which local compression and tranexamic acid should be continued. Simple skin biopsies should be done without any change in anticoagulant use. Excision of lesions (nevi, keratosis, carcinomas) are frequently associated with minor bleedings but rarely $(<5 \%)$ major ones, and optimization of local hemostasis should generally suffice ${ }^{58,59}$. Cataract extraction is an avascular surgery usually done nowadays with phacoemulsion and topical anesthetics - retrobulbar anesthesia is rarely associated with significant bleeding in anticoagulated patients but this could mandate urgent decompression $^{60}$. Minor bleeding (subconjuntival hemorrhage or dot hyphemas) without any vision loss may occur in up to 10 percent of patients but is not a reason for changing the anticoagulant regimen ${ }^{61}$.

\section{NOACs indication}

NOACs have the general advantage over Warfarin of a shorter effect. A typical difficulty with these drugs however is knowing whether or not there is residual anticoagulant activity. Metabolism is slowed in the elderly and with renal insufficiency. Contrary to widespread view, a large number of drugs interact and either increase or reduce the activity or the half-life for elimination of NOACs including:

- antiarrhythmic drugs (quinidine, amiodarone, verapamil);

- $\quad$ calcium channel blockers (diltiazem, verapamil);

- antibiotics, antifungal and antiretroviral drugs (erythromycin and clarithromycin, all iazolics, rifampicin, protease inhibitors [ritonavir etc.]);

- $\quad$ antiepileptics (phenobarbital, carbamazepin, phenytoin);

- $\quad$ antineoplastics (cyclosporin, tacrolimus);

- $\quad$ antacids and proton or hydrogen pump inhibitors.

The first step is trying to know exactly when the last dose was given. Some tests indicate the persistence of anticoagulant effects including increased activated thromboplastin time (aTPT) for dabigatran; or the prothrombin time/INR (point of 
care tests not recommended) for Xa factor inhibitors. Direct measurements of thrombin time (dabigatran) and of Xa activity (other drugs) can help but are far less available or fast and have ill-defined cut-off values to ensure a safe surgery.

The hemorrhagic risk of the proposed intervention should be evaluated. Urgent operations should if at all possible be postponed for 12 or ideally 24 hours. Hopefully specific antagonists/antibodies against thrombin and Xa factor inhibitors will be available in the near future ${ }^{38,39}$. In contrast to Warfarin, preoperative bridging with heparins is not indicated in NOAC treated patients ${ }^{1,62}$.

Any intervention should be made off the last dose peak anticoagulant effect ${ }^{6}$. In minimal risk interventions - dental extractions, cataracts upper or lower endoscopy without biopsies etc. - an interval of 18 to 24 hours after the last dose is suggested, treatment being reinitiated after 6 hours (this corresponds to skipping one dose of NOACs that are given twice daily). Oral tranexamic acid is suggested in dental surgeries.

In low-risk procedures, withholding NOACs for 24 hours in patients with normal renal function is adequate; 48 hours are suggested for higher-risk surgeries. The degree of renal insufficiency should be carefully assessed. In dabigatran treated patients, even small decreases in renal function $(\mathrm{Cr}$ Cl 50-80 mL/min) mandate suspension for 36 hours (low-risk surgeries) or 72 hours (high-risk surgeries); for patients with $\mathrm{Cr} \mathrm{Cl} 30-50 \mathrm{~mL} / \mathrm{min}$ the corresponding time is 48 hours (low-risk) and up to 96 hours (high-risk). For both rivaroxaban and apixaban, the only suggested change is increasing the interval without the drug in patients with $\mathrm{Cr} \mathrm{Cl} 15-30 \mathrm{~mL} / \mathrm{min}$ undergoing low risk surgeries to 36 hours. Current data do not allow a precise recommendation for edoxaban treated patients. NOACs should not be used in individuals with $\mathrm{Cr} \mathrm{Cl}$ below $15 \mathrm{~mL} / \mathrm{min}$ (including those on hemodialysis).

Of special interest to neurologists is the question of surgeries involving the neuraxis - NOACs are not recommended in these patients ${ }^{6}$. Diagnostic lumbar puncture and spinal or peridural anesthesia should only be done after hemostasis has been fully secured (high-risk surgery protocol).
Time to resume drug after surgery should also consider the risks associated with the specific procedure: 6 to 8 hours in low-risk interventions (also for lumbar puncture and spinal and peridural anesthesia), but 48-72 hours in high-risk surgeries. In patients with a high risk of developing VTE, prophylactic or intermediate doses of LMWH after 6 to 8 hours should be given if hemostasis has been adequately obtained (there are no dependable data evaluating the use of small postoperative doses of NOACs in AF patients with this goal $)^{6,62}$. LMWH should be withheld soon after restarting NOACs, which exhibit full effect after 2 hours.

\section{Final remarks}

Neurologists should play an active role in the discussion with cardiologists, surgeons, anesthesiologists, and dentists to reach the best individualized decision regarding antithrombotic perioperative management in AF patients. Decisions should be made considering the objective evaluation of the contrasting risks of thromboembolic recurrence and surgery-related bleeding when withholding anticoagulants or antiplatelet drugs. Uniform care should be pursued and greatly depends on the development of formal institutional protocols. Patients should be evaluated one week before the planned intervention; receive written instructions about anticoagulant suspension, INR testing the day before surgery, the use of parenteral drugs as bridging therapy should follow individualized regimens according to age, renal function and other variables; careful evaluation of hemostasis on days 0 and 1 after surgery; and orientations and regular contact with the Health care team in the following two weeks. In the next few years, further clarification of a number of topics is expected from many studies concerning general surgery (PERIOP-2, BRIDGE) or pacemaker and defibrillation implantation (PACEBRIDGE, BRUISECONTROL) in anticoagulated patients.

\section{References}

1. Healey JS, Eikelboom J, Douketis J et al. Periprocedural bleeding and thromboembolic events with dabigatran compared to warfarin: results from the RE-LY Randomized Trial. Circulation. 2012;126:343-8. http://dx.doi.org/10.1161/CIRCULATIONAHA.111.090464

2. Furie KL, Goldstein LB, Albers GW, Khatri P, Neyens T, Turakhia MP et al. Oral antithrombotic agents for the prevention of stroke in nonvalvular atrial fibrillation: a science advisory for healthcare professionals from the American Heart Association/American Stroke Association. Stroke 2012;43(12):3442-53. Erratum in: Stroke. 2013;44:e20;Stroke. 2012;43:e181. http://dx.doi.org/10.1161/STR.0b013e318266722a

3. Kernan WN, Ovbiagele B, Black HR, Bravata DM, Chimowitz MI, Ezekowitz MD et al. Guidelines for the prevention of stroke in patients with stroke and transient ischemic attack: a guideline for healthcare professionals from the American Heart Association/American Stroke Association. Stroke. 2014;45(7):2160-236. http://dx.doi.org/10.1161/STR.0000000000000024
4. Jauch EC, Saver JL, Adams HP Jr, Bruno A, Connors JJ, Demaerschalk BM et al. Guidelines for the early management of patients with acute ischemic stroke: a guideline for healthcare professionals from the American Heart Association/American Stroke Association. Stroke. 2013;44(3):870-947. http://dx.doi.org/10.1161/STR.0b013e318284056a

5. Meschia JF, Bushnell C, Boden-Albala B, Braun LT, Bravata DM, Chaturvedi S et al. Guidelines for the primary prevention of stroke: a statement for healthcare professionals from the American Heart Association/American Stroke Association. Stroke. 2014;45(12):3754-832. http://dx.doi.org/10.1161/STR.0000000000000046

6. Heidbuchel H, Verhamme P, Alings M, Antz M, Hacke W, Oldgren J et al. European Heart Rhythm Association Practical Guide on the use of new oral anticoagulants in patients with non-valvular atrial fibrillation. Europace. 2013;15(5):625-51. http://dx.doi.org/10.1093/europace/eut083 
7. Douketis JD, Spyropoulos AC, Spencer FA, Mayr M, Jaffer AK, Eckman $\mathrm{MH}$ et al. Perioperative management of antithrombotic therapy: antithrombotic therapy and prevention of thrombosis, 9th ed.: American College of Chest Physicians Evidence-Based Clinical Practice Guidelines. Chest. 2012;141(2 Suppl):e326S-50S. Erratum in: Chest. 2012;141:1129. http://dx.doi.org/10.1378/chest.11-2298

8. You JJ, Singer DE, Howard PA, et al. Antithrombotic therapy for atrial fibrillation: Antithrombotic Therapy and Prevention of Thrombosis, 9th ed: American College of Chest Physicians Evidence-Based Clinical Practice Guidelines. Chest. 2012;141(2 Suppl):e531S-575s. http://dx.doi.org/10.1378/chest.11-2304

9. Anderson MA, Ben-Menachem T, Gan SI, Appalaneni V, Banerjee S, Cash BD et al. Management of antithrombotic agents for endoscopic procedures. Gastrointest Endosc. 2009;70(6):1060-70. http://dx.doi.org/10.1016/j.gie.2009.09.040

10. Bushnell C, McCullough LD, Awad IA, Chireau MV, Fedder WN, Furie $\mathrm{KL}$ et al. Guidelines for the prevention of stroke in women: a statement for healthcare professionals from the American Heart Association/American Stroke Association. Stroke. 2014;45(5):1545-88. Erratum in:Stroke. 2014;45:e95. http://dx.doi.org/10.1161/01.str.0000442009.06663.48

11. Flint AC, Banki NM, Ren X, Rao VA, Go AS. Detection of paroxysmal atrial fibrillation by 30-day event monitoring in cryptogenic ischemic stroke: the Stroke and Monitoring for PAF in Real Time (SMART) Registry. Stroke. 2012;43(10):2788-90. http://dx.doi.org/10.1161/STROKEAHA.112.665844

12. Stroke Risk in Atrial Fibrillation Working Group. Comparison of 12 risk stratification schemes to predict stroke in patients with nonvalvular atrial fibrillation. Stroke. 2008;39(6):1901-10. http://dx.doi.org/10.1161/STROKEAHA.107.501825

13. Avgil Tsadok M, Jackevicius CA, Rahme E, Humphries KH, Behlouli $H$, Pilote L. Sex differences in stroke risk among older patients with recently diagnosed atrial fibrillation. JAMA. 2012;307(18):1952-8. http://dx.doi.org/10.1001/jama.2012.3490

14. Fonarow GC, Reeves MJ, Zhao X, Olson DM, Simith EE, Saver JL et al. Age-related differences in characteristics, performance measures, treatment trends, and outcomes in patients with ischemic stroke. Circulation. 2010;121(7):879-91. http://dx.doi.org/10.1161/CIRCULATIONAHA.109.892497

15. Gage BF, Waterman AD, Shannon W, Boechler M, Rich MW, Radford MJ. Validation of clinical classification schemes for predicting stroke: results from the National Registry of Atrial Fibrillation. JAMA. 2001;285(22):2864-70. http://dx.doi.org/10.1001/jama.285.22.2864

16. Lip GY, Nieuwlaat R, Pisters R, Lane DA, Crijns HJ. Refining clinical risk stratification for predicting stroke and thromboembolism in atrial fibrillation using a novel risk factor-based approach: the euro heart survey on atrial fibrillation. Chest. 2010;137(2):263-72. http://dx.doi.org/10.1378/chest.09-1584

17. Olesen JB, Lip GY, Hansen ML, Hansen PR, Tolstrup JS, Lindhardsen $\mathrm{J}$ et al. Validation of risk stratification schemes for predicting stroke and thromboembolism in patients with atrial fibrillation: nationwide cohort study. BMJ. 2011;342:d124. http://dx.doi.org/10.1136/bmj.d124

18. Van Staa TP, Setakis E, Di Tanna GL, Lane DA, Lip GYH. A comparison of risk stratification schemes for stroke in 79884 atrial fibrillation patients in general practice. J Thromb Haemost. 2011;9(1):39-48. http://dx.doi.org/10.1111/j.1538-7836.2010.04085.x

19. Connolly SJ, Ezekowitz MD, Yusuf S, Eikelboom J, Oldfren J, Parekh A et al. Dabigatran versus warfarin in patients with atrial fibrillation. N Engl J Med. 2009:361(12):1139-51. http://dx.doi.org/10.1056/NEJMoa0905561

20. The Stroke Risk in Atrial Fibrillation Working Group. Independent predictors of stroke in patients with atrial fibrillation: a systematic review. Neurology. 2007;69(6):546-54. http://dx.doi.org/10.1212/01.wnl.0000267275.68538.8d

21. Kallmünzer B, Bobinger T, Kahl N, Kopp M, Kurka N, Hilz $\mathrm{MJ}$ et al. Peripheral pulse measurement after ischemic stroke: a feasibility study. Neurology. 2014;83(7):598-603. http://dx.doi.org/10.1212/WNL.0000000000000690
22. Gaillard N, Deltour S, Vilotijevic B, Hornych A, Crozier S, Leger A et al. Detection of paroxysmal atrial fibrillation with transtelephonic EKG in TIA or stroke patients. Neurology. 2010;74(21):1666-70. http://dx.doi.org/10.1212/WNL.0b013e3181e0427e

23. Sanna T, Diener HC, Passman RS, Crystal AF. Investigators. Cryptogenic stroke and underlying atrial fibrillation. N Engl J Med. 2014;370(26):2478-86. http://dx.doi.org/10.1056/NEJMoa1313600

24. Pisters R, Lane DA, Nieuwlaat R, Vos CB, Crijns HJ, Lip GY. A novel user-friendly score (HAS-BLED) to assess one-year risk of major bleeding in atrial fibrillation patients: The Euro Heart Survey. Chest. 2010;138(5):1093-100. http://dx.doi.org/10.1378/chest.10-0134

25. Lip GYH, Frison L, Halperin JL, Lane DA. Comparative validation of a novel risk score for predicting bleeding risk in anticoagulated patients with atrial fibrillation: the HAS-BLED (Hypertension, Abnormal Renal/Liver Function, Stroke, Bleeding History or Predisposition, Labile INR, Elderly, Drugs/Alcohol Concomitantly) score. J Am Coll Cardiol. 2011;57(2):173-80. http://dx.doi.org/10.1016/j.jacc.2010.09.024

26. Hohnloser S. Stroke prevention versus bleeding risk in atrial fibrillation. A clinical dilemma. J Am Coll Cardiol. 2011;57(2):181-3. http://dx.doi.org/10.1016/j.jacc.2010.09.026

27. Stroke Prevention in Atrial Fibrillation Investigators. Stroke Prevention in Atrial Fibrillation Study: final results. Circulation. 1991;84(2):527-39. http://dx.doi.org/10.1161/01.CIR.84.2.527

28. Petersen P, Boysen G, Godtfredsen J, Andersen ED, Andersen B. Placebo-controlled, randomised trial of warfarin and aspirin for prevention of thromboembolic complications in chronic atrial fibrillation: the Copenhagen AFASAk study. Lancet. 1989;1(8631):175-8. http://dx.doi.org/10.1016/S0140-6736(89)91200-2

29. Stroke Prevention in Atrial Fibrillation Investigators. Warfarin versus aspirin for prevention of thromboembolism in atrial fibrillation: Stroke Prevention in Atrial Fibrillation II Study. Lancet. 1994;343(8899):687-91. http://dx.doi.org/10.1016/S0140-6736(94)91577-6

30. Hellemons BS, Langenberg M, Lodder J, Vermeer F, Schouten HJ, Lemmens T et al. Primary prevention of arterial thromboembolism in non-rheumatic atrial fibrillation in primary care: randomised controlled trial comparing two intensities of coumarin with aspirin. BMJ. 1999;319(7215):958-64. http://dx.doi.org/10.1136/bmj.319.7215.958

31. EAFT (European Atrial Fibrillation Study Group). Secondary prevention in non-rheumatic atrial fibrillation after transient ischaemic attack or minor stroke. Lancet. 1993;342(8882):1255-62. http://dx.doi.org/10.1016/0140-6736(93)92358-Z

32. Patel MR, Mahaffey KW, Garg J, Pan G, Singer DE, Hacke $W$ et al. Rivaroxaban versus warfarin in nonvalvular atrial fibrillation. N Engl J Med. 2011;365(10):883-91. http://dx.doi.org/10.1056/NEJMoa1009638

33. Granger CB, Alexander JH, McMurray JJ, Lopes RD, Hylek EM, Hanna M et al. Apixaban versus warfarin in patients with atrial fibrillation. N Engl J Med. 2011;365(11):981-92. http://dx.doi.org/10.1056/NEJMoa1107039

34. Giugliano RP, Ruff CT, Braunwald E, Murph SA, Wiviott DS, Halperin JL et al. Edoxaban versus warfarin in patients with atrial fibrillation. N Engl J Med. 2013;369(22):2093-104. http://dx.doi.org/10.1056/NEJMoa1310907

35. Connolly S, Pogue J, Hart R, Pfeffer M, Hohnloser S, Chrolavicius $S$ et al. Clopidogrel plus aspirin versus oral anticoagulation for atrial fibrillation in the Atrial fibrillation Clopidogrel Trial with Irbesartan for prevention of Vascular Events (ACTIVE W): a randomised controlled trial. Lancet. 2006;367(9526):1903-12. http://dx.doi.org/10.1016/S0140-6736(06)68845-4

36. Connolly SJ, Eikelboom JW, Ng J, Hirsh J, Yusuf S, Pogue $J$ et al. Net clinical benefit of adding clopidogrel to aspirin therapy in patients with atrial fibrillation for whom vitamin $\mathrm{K}$ antagonists are unsuitable. Ann Intern Med. 2011;155(9):579-86. http://dx.doi.org/10.7326/0003-4819-155-9-201111010-00004 
37. Connolly SJ, Eikelboom J, Joyner C, Diener HC, Hart R, Golitsyn $S$ et al. Apixaban in patients with atrial fibrillation. N Engl J Med. 2011;364(9):806-17. http://dx.doi.org/10.1056/NEJMoa1007432

38. Costin J, Ansell J, Laulicht B, Bakhru S, Steiner S. Reversal agents in development for the new oral anticoagulants. Postgrad Med. 2014;126(7):19-24. http://dx.doi.org/10.3810/pgm.2014.11.2829

39. Vanden Daelen S, Peetermans M, Vanassche T, Verhamme P, Vandermeulen E. Monitoring and reversal strategies for new oral anticoagulants. Expert Rev Cardiovasc Ther. 2015;13(1):95-103. http://dx.doi.org/10.1586/14779072.2015.987126

40. Dewilde WJ, Oirbans T, Verheugt FW, Kelder JC, De Smet BJ, Herman JP et al. Use of clopidogrel with or without aspirin in patients taking oral anticoagulant therapy and undergoing percutaneous coronary intervention: an open-label, randomised, controlled trial. Lancet. 2013;381(9872):1107-15. http://dx.doi.org/10.1016/S0140-6736(12)62177-1

41. Jneid H, Anderson JL, Wright RS, Adams CD, Bridges CR, Casey DE Jr et al. 2012 ACCF/AHA focused update of the guideline for the management of patients with unstable angina/non-ST-elevation myocardial infarction (updating the 2007 guideline and replacing the 2011 focused update): a report of the American College of Cardiology Foundation/American Heart Association Task Force on Practice Guidelines. J Am Coll Cardiol. 2012;60(7):645-81. http://dx.doi.org/10.1016/j.jacc.2012.06.004

42. Berge E, Abdelnoor M, Nakstad PH, Sandset PM. Low molecular-weight heparin versus aspirin in patients with acute ischaemic stroke and atrial fibrillation: a double-blind randomised study. Heparin in acute embolic stroke trial. Lancet. 2000;355(9211):1205-10. http://dx.doi.org/10.1016/S0140-6736(00)02085-7

43. Chen ZM. CAST: randomized placebo-controlled trial of early aspirin use in 20,000 patients with acute ischaemic stroke. Lancet. 1997;349(9066):1641-9. http://dx.doi.org/10.1016/S0140-6736(97)04010-5

44. International Stroke Trial Collaborative Group. The International Stroke Trial (IST): a randomised trial of aspirin, subcutaneous heparin, both, or neither among 19435 patients with acute ischaemic stroke. Lancet. 1997;349(9065):1569-81. http://dx.doi.org/10.1016/S0140-6736(97)04011-7

45. Paciaroni M, Agnelli G, Micheli S, Caso V. Efficacy and safety of anticoagulant treatment in acute cardioembolic stroke: a meta-analysis of randomized controlled trials. Stroke. 2007;38(2):423-30. http://dx.doi.org/10.1161/01.STR.0000254600.92975.1f

46. Saxena R, Lewis S, Berge E, Sandercock PA, Koudstaal PJ. Risk of early death and recurrent stroke and effect of heparin in 3169 patients with acute ischemic stroke and atrial fibrillation in the International Stroke Trial. Stroke. 2001;32(10):2333-7. http://dx.doi.org/10.1161/hs1001.097093

47. Audebert HJ, Schenk B, Tietz V, Schenkel J, Heuschmann PU. Initiation of oral anticoagulation after acute ischaemic stroke or transient ischaemic attack: timing and complications of overlapping heparin or conventional treatment. Cerebrovasc Dis. 2008;26(2):171-7. http://dx.doi.org/10.1159/000145324

48. Broderick JP, Bonomo JB, Kissela BM, Khoury JC, Moomaw CJ, Alwell Ket al. Withdrawal of antithrombotic agents and its impact on ischemic stroke occurrence. Stroke. 2011;42(9):2509-14. http://dx.doi.org/10.1161/STROKEAHA.110.611905

49. White RH, McKittrick T, Hutchinson R, Twitchell J. Temporary discontinuation of warfarin therapy: changes in the international normalized ratio. Ann Intern Med. 1995;122(1):40-2. http://dx.doi.org/10.7326/0003-4819-122-1-199501010-00006
50. Kovacs MJ, Kearon C, Rodger M, Anderson DR, Turpie AG, Bates SM et al. Single-arm study of bridging therapy with low-molecular-weight heparin for patients at risk of arterial embolism who require temporary interruption of warfarin. Circulation. 2004;110(12):1658-63. http://dx.doi.org/10.1161/01.CIR.0000142859.77578.C9

51. Marietta M, Bertesi M, Simoni L et al. A simple and safe nomogram for the management of oral anticoagulation prior to minor surgery. Clin Lab Haematol. 2003;25(2):127-30. http://dx.doi.org/10.1046/j.1365-2257.2003.00499.x

52. Malato A, Saccullo G, Lo Coco L, Caramazza D, Abbene I, Pizzo G et al. Patients requiring interruption of long-term oral anticoagulant therapy: the use of fi xed sub-therapeutic doses of low-molecular-weight heparin. J Thromb Haemost. 2010;8(11):107-13. http://dx.doi.org/10.1111/j.1538-7836.2009.03649.x

53. Douketis JD, Johnson JA, Turpie AG. Low-molecular weight heparin as bridging anticoagulation during interruption of warfarin: assessment of a standardized periprocedural anticoagulation regimen. Arch Intern Med. 2004;164(12):1319-26. http://dx.doi.org/10.1001/archinte.164.12.1319

54. Bruch TP, Mendes DC, Pedrozo JC, Figueiredo L, Nóvak EM, Zétola VF et al. Is point-of-care accurate for indicating thrombolysis in anticoagulated patients on oral anticoagulation treatments? Arq Neuropsiquiatr. 2014;72(7):487-9. http://dx.doi.org/10.1590/0004-282X20140075

55. Borea G, Montebugnoli L, Capuzzi P, Magelli C. Tranexamic acid as a mouthwash in anticoagulant-treated patients undergoing oral surgery. An alternative method to discontinuing anticoagulant therapy. Oral Surg Oral Med Oral Pathol. 1993;75(1):29-31. http://dx.doi.org/10.1016/0030-4220(93)90401-0

56. Ramström G, Sindet-Pedersen S, Hall G, Blombäck M, Alander U. Prevention of postsurgical bleeding in oral surgery using tranexamic acid without dose modification of oral anticoagulants. J Oral Maxillofac Surg. 1993;51(11):1211-6. http://dx.doi.org/10.1016/S0278-2391(10)80291-5

57. Sacco R, Sacco M, Carpenedo M, Moia M. Oral surgery in patients on oral anticoagulant therapy: a randomized comparison of different INR targets. J Thromb Haemost; 2006;4(3):688-9. http://dx.doi.org/10.1111/j.1538-7836.2006.01762.x

58. Alcalay J. Cutaneous surgery in patients receiving warfarin therapy. Dermatol Surg. 2001;27(8):756-8. http://dx.doi.org/10.1046/j.1524-4725.2001.01056.x

59. Syed S, Adams BB, Liao W, Pipitone M, Gloster H. A prospective assessment of bleeding and international normalized ratio in warfarin-anticoagulated patients having cutaneous surgery. J Am Acad Dermatol. 2004;51(6):955-7. http://dx.doi.org/10.1016/j.jaad.2004.07.058

60. Kallio H, Paloheimo M, Maunuksela EL. Haemorrhage and risk factors associated with retrobulbar/peribulbar block: a prospective study in 1383 patients. Br J Anaesth. 2000;85(5):708-11. http://dx.doi.org/10.1093/bja/85.5.708

61. Jamula E, Anderson J, Douketis JD. Safety of continuing warfarin therapy during cataract surgery: a systematic review and meta-analysis. Thromb Res. 2009;124(3): 292-9. http://dx.doi.org/10.1016/j.thromres.2009.01.007

62. Sie P, Samama CM, Godier A, Rosencher N, Steib A, Llau JV et al. Surgery and invasive procedures in patients on long-term treatment with direct oral anticoagulants: thrombin or factor-Xa inhibitors. Recommendations of the Working Group on Perioperative Haemostasis and the French Study Group on Thrombosis and Haemostasis. Arch Cardiovasc Dis. 2011;104(12):669-76. http://dx.doi.org/10.1016/j.acvd.2011.09.001 